\title{
Culinary Transitions: Understanding the Kitchen Space through Advertisements
}

\author{
Kashyapi Ghosh ${ }^{1}$ and V. Vamshi Krishna Reddy ${ }^{2}$ \\ 1Ph.D Scholar, IIT Tirupati. ORCID: 0000-0001-5394-6076. Email: hs18d504@iittp.ac.in \\ ${ }^{2}$ Assistant Professor, University of Hyderabad. ORCID: 0000-0003-0383-6287 \\ Email: vamshi.vemireddy@uohyd.ac.in
}

\begin{abstract}
The kitchen is a ubiquitous space in the Indian domestic life. Yet there hasn't been a lot of academic discourses around it possibly owing to its mundane nature. In this article, I aim to look into the gendered nature of the space through advertisements. Advertisements are digital documents of everyday life This article deliberates on the notion that the kitchen space in urban India is undergoing a change in representation and participation. This change is reflected in the advertisements, created keeping in mind the perception of its viewers. The gendered segregation of work done in the home space have been deliberated by a number of scholars. This article problematises those viewpoints and challenges DeVault's notion of "womanly conduct" through the narrative of the advertisements.
\end{abstract}

Keywords: advertisements, gender, kitchen space.

\section{Introduction}

As a Times of India commercial locates,

"There are two Indias in this country. One India is straining at the leash, eager to spring forward and live up to all the adjectives that the world has increasingly been showering upon us. The other India is the leash. One India says, "Give me a chance and I'll prove myself." The other India says, "Prove yourself first and maybe then you'll have a choice." One India lives in the optimism of our hearts. The other lurks in the scepticism of our minds" (quoted in O'Barr, 2008)."

Between these two contrary states of scepticism and optimism is an accretive space which is where I choose to converse about the Indian kitchen space. The world which has perennially loaded India with adjectives, is also keen on the variegated cuisine of India and its vast range encompassing the north, south, east, west. It has been realigned into two categories. One, the younger India, which is leaping headlong into the stream of globalisation with modular and cloud kitchens, food delivery mobile applications; the other, slightly older one which thrives on the stereotypes of "ghar ka khana" (home-made food). It is in this polarity that I aim to read the shifting dynamics of the Indian kitchen space through television commercials as tools. The culinary image of the Indian

This Open Access article is published under a Creative Commons Attribution Non-Commercial 4.0 International License (http://creativecommons.org/licenses/by-nc/4.0/), which permits non-commercial re-use, distribution, and reproduction in any medium, provided the original work is properly cited. For citation use the DOI. For commercial re-use, please contact editor@rupkatha.com. 
kitchen space is quite different from that of other nations not merely in its vibrant flavours but also in the intensity of its gendered nature.

Kitchen has had multifarious meanings ranging from "invariably offstage" to "heart of the home" to a foreground for women's unpaid labour as well as "a sacred space" (Appadurai,1988; Busch,1999; Ray,2010). Despite the innumerable adjectives that accumulates around the kitchen space, in India it is always in a stage of metamorphosis, never fitting into a singular epithet. The idea of a culinary space in India can be defined as labour intensive and technique-based (Sen, 2015). The dual factors of labour and technique is mostly under the close supervision and jurisdiction of women; both housebound and working. Kitchen-for most middle-class Indian children/ adults is an all-encompassing image of their mothers, grandmothers, aunts churning out delicacies at odd hours of the day; stirring, grinding, mixing to create lip-smacking comestibles. There is a lack of a consolidated male figure as a matter of fact holding the reins of the household or engaging in such activities. There is nothing a man has got to do with the kitchen is an adage used by old women to prevent an encroachment of their space and to maintain the status quo of the society. Essentially, men build houses, women make homes. This status quo prevents the blurring of the gendered space and keeps it untainted and untraversed. Men usually cook or learn to engage in domestic cooking when there is "no woman in the household" (Coxan, 1983, p.173) and it is an absolute survival necessity. However, there is an undiminishing male presence in the burgeoning professional kitchens and cookery shows. These cookery shows have given unparalleled fame to the likes of Sanjeev Kapoor, Vikas Khanna, Ranveer Brar etc and carefully carved the image of the male culinary expert in the professional kitchen. In the Indian domestic kitchen space, however, there is a gaping inequality. Utsa Ray (2010) opines," "While at home, cooking was considered a feminine task, when translated into being a profession it became a male job, making for a distinct demarcation in the realm of culinary practice" (p.63), this automatically gives men the freedom to escape from the "home-kitchen"; men are not liable to provide unless it is for the greater professional ambition. In our everyday lives, one rarely finds a man moving out of his own accord into the kitchen owing to this gendered demarcation of the space and more because there is no social implication on a man to engage in house work. As Meredith Abarca points out, "In a mother's absence, the wife cooks", the role reversal always occur within the female authorities making the kitchen 'a hegemonic site of women's natural, rightful place' (2006, p.19). The baton is rarely passed over to the male owing to multiple societal norms and questions of gender performance. Though there are complains about the monotony of the work (chopping, cooking, cleaning, serving), yet they never wilfully vanquish their space and often complain about the man entering the kitchen, leaving it unclean thereafter, increasing the amount of work to be done. Even when they come to terms with the reluctant surrender; they are haunted by the gendered practices of engaging in food-work and how it is unacceptable to neglect one's 'duties.' Women are conditioned to believe that it is their foremost duty to perform housework and play the role of the perennial nourisher. However, this invisibility, this 'gaping inequality' as I have mentioned formerly is undergoing a modification in the greater context of food work or undivided household labour within the kitchen space. From the beginning of the century, the food culture began to expand its territories with celebrity chefs, gastro-magazines and "chow hounding" websites. The twenty-first century saw the evolution of the kitchen-space into a cloud kitchen to facilitate the transportation of cooked food, thereby reducing the burden of cooking (at least in 
the urban areas). With the increase in number of women in the workforce, the sole responsibility of household work shifted. It is important to understand that it is not only the burden of cooking that gets reduced, but the concept of the traditional domestic kitchen space along with culinary practices and epistemologies stand in a transitional space. This transitional space is where we can argue, postulate, problematise the theories of gendered space and household labour in the everchanging scape of the urban society haunted by technology. The cloud kitchen is one such boon/bane of technology. It is a post "millennial" idea of having makeshift kitchens near residential areas or housing societies to enable faster and easier delivery of food. Thus, the cloud kitchen stands as a median between the domestic kitchen and the brick-and-mortar restaurant kitchen. The principal aim to incorporate the concept of the cloud kitchen with the greater narrative of the domestic kitchen space is to identify the flux in "doing kitchen" or "doing food work". The present generation have created their own niche in terms of their lifestyle, status, profession and understand the entire corpus of the kitchen space differently with the introduction of start-up food delivery applications like Zomato, Swiggy, UberEats which work on the cloud kitchen model and get food delivered at the doorstep through their smartphone applications. Zomato, Swiggy et al are often the "hunger saviour" for the younger generation who do not relate to the traditional "practices of cooking" and feeding work. The idea of cooking, eating, "organisation of the provision of meals" (Anne Murcott, p.1) along with the space where all such meanings are generated is altered and attains a redefinition. The impact of the space along with the activities that are centred around it is reduced in importance because of the changing lifestyles. With more working couples, the concept of cooking and the kitchen space as a highly gendered space looms in a question. Who owns the space? Who does the cooking? How do you find gendered norms redefined? These questions have polyvalent answers with respect to participation and generic representation in the kitchen space.

\section{Theoretical Framework}

The kitchen as a site of gendered segregation of work involving the upkeep of a family has been a matter of contention for gender theorists, sociologists (Charles and Kerr, 1988, deVault 1991, Warde, 1997, Giard, 1998). This gendered segregation and upkeep places the female at the centre of the discourse of domestic labour. The geopolitical aspect of the kitchen gives rise to the question of admission and of space as ear-marked for a particular gender. This territorialisation of the space is often considered a problematic aspect in the purview of the feminist approach. Some want to own the space, the others want to abandon it, while a group of others want to get rid of the space and the disagreement is never-ending. Food studies scholars who have created a significant scholarship in the inter-disciplinary area of food, culture and society, have paid little attention to the kitchen space as a unique identity in the domestic arena and the fact that cooking spaces can be made inclusive into the broader discipline. The kitchen space is a hyphenated identity in this study; read through multiple foci of space, gender, etc. Even though cooking has almost always been paralleled to monotony, one requires a certain amount of skill and expertise for the act; whether the skill is mandatorily gendered or not is another question. Most feminist scholars have understood the space as a rather repressive, abject space where women cannot claim their own (Floyd, 2004) advocating for a "kitchen-less" society for an emancipation of the entire clan. However, some scholars have realised the need to understand and re-think the kitchen 
space and cooking within the feminist discourse as a rejoinder for the gap between theory and praxis. (Haber, 1997, Avakian, 1998, Abarca, 2006, Christie, 2008). These thinkers have claimed that there is a sense of solidarity, self-expression when women speak from within the spaces, they consider their "own". The gap which causes a divide between the contradicting propositions of gender theorists. They are of the belief that it provides an unusual bonding with fellow women, where "she is not in competition with others" (Choma-Sampson and Sampson-Choma, p.106) and how "women redefined an act of labour and turned it into the labour of love" (Ray, p.66). There is a need to understand the space as one not only of self-inflicted repressions but of protest and resilience. A space which culminates into varying degrees of "freedom, self-awareness, subjectivity and agency" as well as where "unity, acceptance, love and acceptance flourish" (Abarca, 2006, p.19; Choma-Sampson and Sampson-Choma,2014, p.106). The kitchen space isn't always about the binaries but about the individuality of one's experience with the space. It is important to ascertain that in between the dialectic associated with the kitchen space, I do not argue for one over the other but aim to make analytical deductions about the cusp of transition that it is going through in the contemporary epoch in urban India and as observed in the selected sample of advertisements.

\section{Reading the kitchen space through advertisements}

To understand the transition in the kitchen space which I talk about throughout the course of the article, it is important that we look around to document these changes. These changes are more clearly observed in digital consumption.; advertisements being one of them. In today's rapidly transiting global village, we notice and consume advertisements everywhere from highways to commute stations to traffic signals apart from the traditional mediums like television and radio. Advertisements have been used as cultural texts to problematise and analyse practical arguments that can be grounded within the kitchen-space- not an ordinary space but a highly contested one; witness to multiple layers of conversation and communication. These advertisements are important on two grounds: one, it reconceptualizes the ideas of mandatory labour. Two, it projects the kitchen space as a liberal space which celebrates voluntary participation. The advertisements are from different timelines but within the same thematic strand. The rationale behind choosing these advertisements in particular is their congruence with the greater idea of the kitchen space. Though the advertisements do not visibly depict/convey the kitchen space in all its ambivalences, but it essentially anchors the space, keeps it in the background. In this article, contemporary Indian television advertisements are accessed from YouTube (A popular video streaming website) and used to understand the change that has occurred in the Indian sensibility with regard to the kitchen space. A textual and thematic network analysis of the advertisements are conducted to read into the politics of the kitchen space.

The article is laid out around some major viewpoints. First, the change in the depiction of the kitchen from a female bastion to one that initiates if not promotes volitional participation and creates a valuable discourse around it; quite influential in changing the societal norms around food, cooking and gendered practices. Volitional participation in housework was an extremely unusual concept in ancient India but with the changing nature of the society it is becoming more commonplace and acceptable. However, it is important to remember that watching the 
5 | Culinary Transitions: Understanding the Kitchen Space through Advertisements

advertisement doesn't guarantee participation among its viewers but merely initiates a conversation about it. Second, the kitchen space and the range of metaphorical meanings it generates from a pedagogical space to a gender-neutral space. The main objective of reading advertisements is to understand the consistent range of cultural meanings it generates and how they can be categorised as "message- producers". The messages analyse the precarious relationship between the kitchen space and gender. With the Indian society going through a transition, the popular culture reflects that flux in different forms of the media. In the following sections, this transition in the kitchen space is traced.

\section{The kitchen as a conjugal-homosocial space}

In this section of the article, the idea of voluntary participation will be deliberated through the advertisements chosen on the basis of similar thematical grounds. Here, I argue that the kitchen space can be a shared space, provided both the man and woman are in agreement with the culinary preoccupations. By claiming it as a shared space, I do not argue for a mandatory shared space where men/women should compulsorily engage in food work. In the Indian scenario, it is difficult to attain a social equality that would allow men and women to choose their culinary stance.

The advertisements are in themselves narratives of how women are not always willing to uphold the idea of a kitchen as a "female bastion". The first advertisement (https://www.youtube.com/watch?v=aS_wwC8P12I) portrays an arranged marriage scenario, prevalent in the Indian societal setup where a young girl who is new to the circumstantial changes in her life tries to put forth her views against such an "arrangement of marriage". She is of the opinion that the mere consumption of samosas (an Indian snack item) doesn't guarantee a good partner. In the Indian arranged marriage system, there is a custom of visiting the bride's home with the prospective groom. This creates an occasion of sharing sweets, snacks and other edibles. More often than not, the bride is seen carrying a plate full of sweets to show off her 'homemaking' skills. Conventionally, the girl is posed questions about her cooking skills and held primarily responsible for household labour. The father, also the patriarchal head of the family lays down his cards of agreement for the marriage. He makes it precise that the prospective groom must know the basics of household labour as a prerequisite for marriage, else the proposal of marriage would be called off. The groom's mother tries to defend her son claiming that he is incapable of boiling water and the maximum limit of his cooking skills is preparing noodles using a microwave oven. The father vehemently disagrees to such a match, retorting that it is impossible for his daughter to survive on plain noodles. The climax of the advertisement arrives when the gentleman (the prospective groom) steps in to the argument bargains for a week's time to learn the necessary skills and invites them to test his eligibility skills. The kitchen, though invisible has been foregrounded in this advertisement. Despite the invisibility, the question of responsibility towards food-work arises; who cooks and who eats and who in turn shares the responsibility remains some of the pertinent questions to be asked before entering a nuptial bond. As Bordo et al opines "The kitchen is where crucial aspects of culture and ethnicity are maintained, but it may also be the site where assimilation occurs". The kitchen, in this advertisement, is representative of the cultural meaning where men are not expected to possess culinary skills but women should 
own them. However, the assimilation occurs towards the end where the man agrees to learn the skill and the marriage is fixed. Having talked about assimilation, it is important to understand that such an 'assimilation' is not an everyday occurrence in the Indian societal structure. Another important aspect within the advertisement is the man-man conversation about cooking and entry into the kitchen space. It is the girl's father who insists on cooking as a prerequisite skill. On the contrary, it is the boy's mother who gets defensive about his lack of skills. The principal aim of the advertisement is not to highlight the fact that a man must know how to cook before he is married, it is however to read a man's voluntary participation in the upkeep of household affairs. This participation is one of the dimensions of the changing dynamics of the kitchen space.

Appliances and applications go hand in hand; in the contemporary world of technological revolution, almost everything that we observe, read come in the form of software applications. In such a revolutionary world, even cooked food comes in the form of an application lifting off the mandate of housework being coterminous to women's work. Swiggy is an India based start-up working on the cloud kitchen model, delivering food to people at their doorsteps. Among its numerous advertisements targeted at the younger generation, one particularly stands out. It opens with three women of the same family, sitting together in close proximity and sharing a cosy camaraderie. The youngest one asks her mother to prepare her favourite curry (the obsession with "ghar ka khana" which I mentioned at the outset) who in turns asks her mother to do the same. Thereby, revealing the relationship between these three women. The expected, conventional reaction of an Indian mother would be to rush towards the kitchen and prepare the meal that has been asked by their children. However, the lady in question abandons the stereotypical notion of woman moving into the cuisine to provide sumptuous meals which DeVault calls the "womanly" conduct (1991). Instead, she takes resort to a food delivery application to order the same delicacy. This action, in a unique way complicates the idea of "womanly conduct" with the implosion of technology. The food delivery applications work on a kind of cloud kitchen model where they take food from different restaurants and deliver it to the customer's doorstep. In such an arrangement, working in the kitchen and fulfilling one's maternal instincts become a choice, not one which is forced upon owing to the gendered nature of the roles (https://www.youtube.com/watch?v=mSOSHjwAnbk).It is this freedom, that the grandmother figure in the advertisement upholds much to her grand-daughter's dismay. Thereby proving that the kitchen space is a choice, not necessarily a scheduled monotony where you ought to perform your gendered duty. The kitchen space, then, rises from its standardized role of keeping women within their familial bounds to a cusp of revolution which is embedded within an essentially repressive space: it never claims to make homes "kitchen-less" but enables one to find solace, resilience, creativity as well as to withdraw from the space whenever necessary. Here, the initial reaction of the grand-daughter and the daughter and their subsequent acceptance is of importance. As a young girl, she doesn't necessarily understand cooking as a "labour of love" and the pressing need for a woman to perform in the kitchen at the fancies and demands of other members of the family.

The father, the young lady and the grandmother in the aforementioned advertisements do not accept the kitchen space as an emasculation or a site of mandatory labour and move ahead from these gendered conclusions. Women in the kitchen space create their own voice to step out, make a difference and introduce an alternative discourse; a discourse which is neither a 
compromise of masculinity nor a reinforcement of femininity. Men, on the other hand, come forward to question the "mandatory labour" that confines mothers and daughters to the kitchen to learn anew.

\section{The Kitchen as a pedagogical space}

Rachael Scicluna in her book Home and Sexuality: The Other Side of the Kitchen (2017), writes in detail about the multiple dimensions that the kitchen engenders through an ethnographical study of elder lesbians in London. One of the arguments being the kitchen as a pedagogical space where children tend to learn a lot. In this section, I borrow this argument from Scicluna's work and contextualise it with two advertisements and read the kitchen as a pedagogical space where instructions are taken and imbibed. I begin with an advertisement that pushes a few milestones to attain the essence of male participation in household labour. In this advertisement (https://www.youtube.com/watch?v=QvCMEGIMuhg) a young boy is seen working alongside his father in the kitchen. As his father chops and gets the ingredients ready, the young boy with his staggering hands brings in items for the meal preparation. He walks around the kitchen sometimes unable to lay his hands on appliances owing to his height. His father comes to his aid, $\mathrm{p}$ roviding him a platform to manoeuvre around the kitchen and they both fix a meal together. Just as they are ready to set the table, the mother enters the home from work, all surprised by the innovative nature of their activities. In between the advertisement, the voiceover narration says, "They say a kitchen can teach a boy many things but a helping hand will go a long way", "that everything and everyone needs their own space". The advertisement successfully creates a gender-neutral scape, it doesn't try to highlight the man working in the kitchen nor does it try to promote it as a Herculean task as is common in Indian homes. On the contrary, the man is shown at ease working in the kitchen, teaching his son by example. The advert ends with, "This is where he will learn to become a better man". Here, I argue, that the changing fabric of the societal structure demands the man to take part in household activities and this advertisement coalesces it. By teaching the young child to get involved in the culinary space, the kitchen becomes a "pedagogical space" (Scicluna 2017) where he receives his lessons on making the kitchen- a gender neutral space by extending a helping hand and manoeuvering through the space without discomfiture. However, the entry of the male into the kitchen making him "a better man" is a slightly far-fetched idea in the Indian scenario. In India, getting a man into the kitchen is an uphill task. The nature of this uphill task will be divulged in the following advertisement. This advertisement (https://www.youtube.com/watch?v=X0fsaJ_hIP0\&t=2s) revolves around a contemporary nuclear family of three; mother, son and daughter-in-law. The mother-in- law gives away an image of a strict woman who believes in the middle-class hierarchy of feminine domesticity where the daughter-in-law is supposed to willingly take over the household responsibilities. Here, it is important to understand that the Indian household system runs in a strict sense of hierarchy; hierarchy that is maintained and reinforced by the female members from mother-in-law to daughter-in-law or from mother to daughter. As Appadurai notes that in urban kitchens, there is a significant amount of interaction between "female householders" (Appadurai,1988); these interactions often are more about the decorum of the kitchen space or the sharing of recipes which are handed down from generation to generation. The lady in 
question, the mother-in-law, has an argument with her son, regarding the preparation of morning tea, so much so that she takes her phone and tries to reach out to the girl's parents to reinforce the regulations. This "transgression of conventional norms of kitchen behaviour" (Floyd, 2004) is unacceptable to the mother-in-law. The man on the other hand fiddles with the television remote, waiting for tea to be served to him. The preparation of food and its concerns immediately pushes the man in a backseat, preventing him from taking the bold step of entering the kitchen. The son intervenes, asks his wife to prepare tea who rejects the idea, plonks herself on the sofa and starts scrolling through her phone. Forcing "the man of the house" to prepare tea for everyone. Marie Christie in her ethnographic study on Mexican families observes that men walk into the kitchen only to be served food and they leave the space thereafter (2008). This finding can be similar for most Indian homes. In this case, however there is no escapade for the man in question. In the meantime, mother and daughter-in-law reveal their subtle plan to introduce "the man of the house" to the odd jobs of the kitchen, urging him to prepare a breakfast delicacy, much to his dismay. Sananda Roy opines "Given joint family practices in India, the kitchen is the shared female space. As already mentioned, kitchen and food have been emblematic of restrictive and nonintellectual female domains-in almost all cultures" (2021, p.47). Here the "non-intellectual female domains" are transformed by the women into a domain of coerced inclusion. The man is reluctant to enter the kitchen space but there is a subtle force, a pedagogical act which makes him aware of the necessity of participation in food-work. The two women perform the role of strict instructors, giving important lessons for life to "the man of the house". They make it clear that being the "man of the house" doesn't give him perks but makes him a part of an inclusive policy where work done in the kitchen becomes shared; not an individual's 'burden'. Here, the daughterin-law and mother-in-law become allies to target the "man of the house" and teach him important lessons about kitchen work. As Meah (2014) notes that women are reluctant to give up their domain and it causes discomfort to see their male counter-parts masculinity in a state of compromise. However, in this advertisement, the women intentionally throw a gauntlet of surprise to the man, making it clear that food-work isn't their sole responsibility. The purpose of such an analysis is to understand the changing representation of the Indian kitchen space with respect to "food work" and how the change is getting reflected in the form of adverts. Masculinity is a "repetitive discourse", but the analysis tries to relook at the idea of masculinity and break the loop of reiteration along with the understanding of the kitchen space as a pedagogical space. This idea of a kitchen as a pedagogical space is important not only for a gender-neutral environment but also to create a different narrative within the isolation and the invisibility that the kitchen space is met with.

\section{Conclusion}

Through a thematic network analysis and textual analysis, the twin themes of the kitchen space as a conjugal and pedagogical space are depicted with the help of the advertisements. Through this study, I aim to understand the gendered nature of the space as well as its transitional aspect in the Indian context. The transitional nature of the Indian kitchen space is a narrative of choices. A 
9 | Culinary Transitions: Understanding the Kitchen Space through Advertisements

choice that is equally powerful and important to understand when we talk about the changing socio-cultural fabric of India, no longer anchored to its traditional beliefs. Understanding the difficulties of traversing the ethos of the kitchen space in its entirety, I choose to read the advertisements as texts which discuss the gendered nature of the space only, not the concerns of class. Therefore, there is an intermingling of the modular kitchen, the cloud kitchen and the mundane kitchen in this analytical pastiche.

\section{References}

Abarca, M. E. (2006). Voices in the Kitchen: Views of food and the world from working-class Mexican and Mexican-American women. Texas and A\&M University Press.

Appadurai, A. (1988). How to Make a National Cuisine: Cookbooks in Contemporary India. Comparative Studies in Society and History, 30(1), 3-24. doi:10.1017/S0010417500015024

Avakian, A. V. (1997). Introduction. In A.V. Avakian (Ed.), Through the Kitchen Window: women explore the intimate meanings of food and cooking (pp.1-9). Beacon Press.

Bibaindia (2015, December 29) Change The Convention [Video]. YouTube. https://www.youtube.com/watch?v=aS_wwC8P12I

Bordo,S., Klein,B., Silverman, M.K.(1998). Missing Kitchens. In H. J. Nast and S. Pile (eds.). Places Through the Body (pp. 54-68). Routledge.

Busch, A. (1999). Geography of Home: Writings on Where We Live. Princeton Architectural Press.

Charles, N., \& Kerr, M. (1988). Women, Food and Families. Manchester University Press.

Choma-Sampson, T., \& Sampson-Choma, T. (2014). Come, Dine at my Table: The Enactment of Safe Spaces in the Cookbooks of Maya Angelou. CLA Journal, 58(1/2), 105-117. Retrieved June 25, 2021, from http://www.jstor.org/stable/44326223

Christie, M. E. (2008). Kitchenspace: Women, Fiestas, and Everyday Life in Central Mexico. University of Texas Press.

Coxon,T. (1983). Men in the Kitchen: notes from a cookery class. In A. Murcott (Ed.) The Sociology of Food and Eating (pp 172-177). Gower Publishing Company.

de Certeau, M., \& Giard, L. (1998). The Practice of Everyday Life (Vol.2). University of Minnesota Press.

DeVault, M. L. (1994). Feeding the family: The Social Organization of Caring as Gendered Work. University of Chicago Press.

Floyd, J. (2004). Coming out of the kitchen: texts, contexts and debates. Cultural Geographies, 11(1), 61-73. https://doi.org/10.1191/1474474003eu293oa

Haber, B. (1997). Follow the food. In A. Avakian (Ed.), Through the Kitchen Window: women explore the intimate meanings of food and cooking (pp. 65-74). Beacon Press.

Meah, A. (2014). Reconceptualizing power and gendered subjectivities in domestic cooking space., Progress in Human Geography, 38(5), pp. 671-690 https://doi.org/10.1177/0309132513501404

Murcott, A. (1983). Introduction. In Murcott, A (Ed.), The Sociology of Food and Eating (pp 1-5). Gower Publishing Company

O'Barr, W.M. (2008). Advertising in India. Advertising \& Society Review 9(3), 1-33. doi:10.1353/asr.0.0011. 
$\mathrm{p}$ से picture. (2019, October 22). Sabhyata Diwali ad - Milibhagat. [Video]. YouTube. https://www.youtube.com/watch?v=XOfsaJ_hIP0\&t=2s

Ray, U. (2009). Aestheticizing labour: an affective discourse of cooking in colonial Bengal. South Asian History and Culture, 1(1), 60-70, DOI: 10.1080/19472490903387217

Roy, S. (2021) What Do You Want for Dinner, Honey?: The Subversive Power of Food. In S. Malhotra, K. Sharma \& S. Dogra, Food Culture Studies in India: Consumption, Representation and Mediation (pp 43-48) Springer. https://doi.org/10.1007/978-981-15-5254-0

Scicluna, R. (2017). Home and Sexuality: The Other Side of the Kitchen. Palgrave Macmillan.

Sen, C. T. (2015). Feasts and Fasts: A History of Food in India. Reaktion Books.

Sleek by Asian Paints. (2019, July 10). Modern Kitchens for Modern Minds. [Video]. YouTube. https://www.youtube.com/watch?v=QvCMEGIMuhg

Swiggy India. (2018, October 22). Why lose out on quality family time when you have Swiggy? Order now. [Video]. YouTube. https://www.youtube.com/watch?v=mSOSHjwAnbk

Warde, A. (1997). Consumption, Food and Taste. Sage.

${ }^{1}$ Kashyapi Ghosh is working as a Ph.D Scholar in the Department of Humanities and Social Sciences, Indian Institute of Technology, Tirupati. For her doctoral thesis, she is looking at the changing dynamics of the kitchen space in India.

${ }^{2}$ Dr. V Vamshi Krishna Reddy is working as an Assistant Professor at the Centre for Comparative Literature, University of Hyderabad. His broad area of interest lies in Film Studies, Cultural Studies and Critical Theory. 